\title{
PENGEMBANGAN PROGRAM APLIKASI ENHANCED MACHINE CONTROL DENGAN PYTHON UNTUK METODE INTERPOLASI NEWTON
}

\author{
Alexander A S Gunawan'; Jimmy Linggarjati² \\ ${ }^{1}$ Mathematics \& Statistics Department, School of Computer Science, Binus University \\ Jln. K.H. Syahdan No. 9, Palmerah, Jakarta Barat 11480 \\ aagung@binus.edu \\ ${ }^{2}$ Computer Engineering Department, Faculty of Engineering, Binus University \\ Jln. K.H. Syahdan No. 9, Palmerah, Jakarta Barat 11480 \\ jimmyl@binus.edu
}

\begin{abstract}
Nowadays, one of industrial main problems is the flexibility of machines to be customized since they are designed based on certain standard. This research develops software for CNC (Computer Numerically Controlled) machine in order to execute the Newton Interpolation using Python. The platform used in the CNC machine is EMC (Enhanced Machine Control) and GUI (Graphical User Interface) AXIS on the operating system Linux Ubuntu. The Newton interpolation is used to create a curve based on several point determined by user. By converting this curve into G-Code, which could be read by CNC machine, the machine can move according to curve designed by user. This research is an initial study to customize the CNC machine and will continue to fulfill the user needs. This research obtained a program that is able to run well up to 4 input pairs. The higher number inputs will cause the oscillation in the interpolation curve.
\end{abstract}

Keywords: CNC, EMC, AXIS, Newton interpolation, G-Code, Python

\begin{abstract}
ABSTRAK
Masalah yang dihadapi dunia industri saat ini ialah mesin yang kurang fleksibel untuk diubahsesuaikan karena dirancang oleh manufaktur yang berdasarkan standar tertentu. Penelitian ini mencoba untuk mengembangkan program untuk mesin CNC (Computer Numerically Controlled) agar mesin tersebut dapat menjalankan metode interpolasi Newton menggunakan bahasa pemrograman Python. Platform yang digunakan dalam mesin CNC ini adalah perangkat lunak EMC (Enhanced Machine Control) dengan menggunakan GUI (Graphical User Interface) AXIS pada sistem operasi Linux Ubuntu. Metode interpolasi Newton digunakan untuk membentuk suatu kurva dengan sejumlah titik tertentu. Dengan mengubah kurva tersebut menjadi G-Code yang dapat dibaca oleh mesin CNC, mesin tersebut dapat bergerak mengikuti kurva yang sudah dibuat pada perangkat lunak. Penelitian ini merupakan contoh bagaimana cara untuk mengubahsesuaikan mesin CNC sehingga dapat sesuai dengan kebutuhan pemakai. Hasil pengujian dapat berjalan dengan baik sampai dengan empat pasang data masukan dan untuk masukan yang lebih banyak akan menimbulkan osilasi pada kurva hasil interpolasi.
\end{abstract}

Kata kunci: CNC, EMC, AXIS, interpolasi Newton, G-Code, Python 


\section{PENDAHULUAN}

Awal lahirnya mesin CNC (Computer Numerically Controlled) bermula dari 1952 yang dikembangkan oleh John Pearseon dari Institut Teknologi Massachusetts, atas nama Angkatan Udara Amerika Serikat (Smid,P, 2003). Sekarang ini, fungsi mesin CNC semakin berkembang untuk menjawab tantangan dunia manufaktur yang semakin modern. Selain itu ketelitian mesin CNC telah dapat mencapai 20 mikron (0.02 milimeter) atau bahkan bisa lebih presisi. Dengan adanya mesin CNC yang dilengkapi perangkat lunak CAM (Computer Aided Manufacturing), seorang operator cukup membuat gambar kerja dari benda yang akan dibuat dengan mesin CNC pada PC (Personal Computer). Hasil gambar kerja dapat dieksekusi secara simulasi untuk melihat pelaksanaan pengerjaan benda kerja di mesin CNC melalui layar monitor. Jika hasil eksekusi simulasi sudah sesuai dengan yang diharapkan, program dilanjutkan dengan eksekusi program mesin. Dengan cara ini, waktu yang diperlukan untuk menyelesaikan pekerjaan yang menggunakan model serupa menjadi jauh lebih cepat dan efisien.

Dalam Starovešk, et al. (2009), dijelaskan pemanfaatan sistem kontrol arsitektur terbuka berbasis Linux (OAC) sebagai platform untuk Mesin CNC Milling. Sedangkan di penelitian ini, mesin $\mathrm{CNC}$ yang digunakan juga dirakit sendiri, dengan menggunakan perangkat lunak open source EMC (Enhanced Machine Control) dengan menggunakan GUI (Graphical User Interface) AXIS pada sistem operasi Linux Ubuntu. Penelitian ini mencoba untuk mengembangkan program untuk metode interpolasi Newton menggunakan bahasa pemrograman Python. Hal ini dimaksudkan sebagai contoh bahwa mesin CNC tersebut dapat dikustomisasi oleh pengguna untuk berbagai keperluan yang spesifik sehingga tidak tergantung lagi dengan perangkat lunak standar yang ada di pasar.

\section{METODE}

\section{EMC(Enhanced Machine Controller)}

EMC(Enhanced Machine Controller) adalah suatu perangkat lunak komputer untuk mengontrol mesin seperti milling machines, bubut, plasma cutters, cutting machines, robots, hexapods, dan lain lain. EMC adalah perangkat lunak Open Source berlisensi di bawah GNU General Public License dan GNU Lesser General Public License (GPL dan LGPL).

EMC2 merupakan pengembangan dari perangkat lunak EMC. Ada empat komponen utama untuk perangkat lunak EMC2, yaitu: kontroler gerak, kontroler I/O diskrit, modul untuk mengkoordinasi kontroler, dan antarmuka pengguna grafis (Getting Started Guide, 2011). Selain itu ada fasilitas disebut HAL (Hardware Abstraction Layer) yang memungkinkan penyesuaian konfigurasi EMC2 tanpa perlu mengkompilasi ulang.

EMC2 ini juga menyediakan: (1) beberapa antarmuka untuk pengguna grafis termasuk satu untuk layar sentuh; (2) interpreter untuk "G-Code" (RS-274 alat mesin bahasa pemrograman); (3) gerakan sistem mesin secara realtime dengan tampilan-depan; (4) pengoperasian mesin elektronik tingkat rendah seperti sensor dan motor; (5) perangkat lunak PLC yang dapat diprogram dengan ladder diagram; (6) kemudahan instalasi dengan CD-Live. Gambar 1 menunjukkan diagram blok sederhana yang menunjukkan sistem EMC2 untuk mesin 3-axis. Diagram ini menunjukkan sistem motor stepper. PC dengan Linux sebagai sistem operasinya, digunakan untuk mengendalikan drive stepper motor dengan mengirimkan sinyal melalui port printer (paralel). Sinyal-sinyal (pulsa) yang dikirim ini membuat drive stepper motor dapat bergerak. 


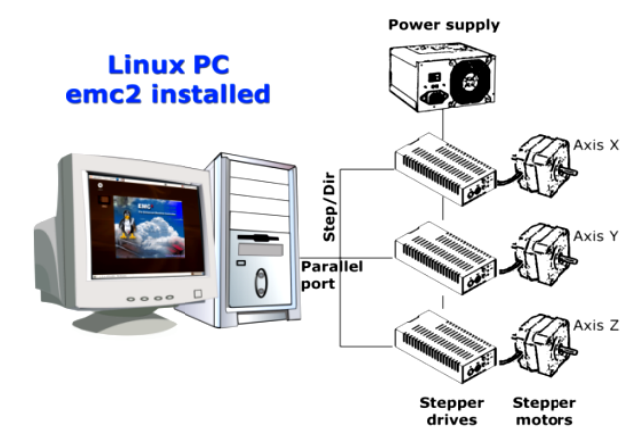

Gambar 1. EMC2 Controlled Machine

\section{AXIS Interface}

AXIS Interface merupakan salah satu tampilan antar muka dari EMC2. AXIS adalah default interface pada EMC2 yang secara aktif dikembangkan oleh para penggunanya (User Manual, 2011). AXIS Interface ini dapat dikonfigurasi dengan menambahkan Virtual Control Panel untuk menyesuaikan bentuk tampilan pada saat menjalankan program EMC2 supaya sesuai dengan kebutuhan pengguna. Tampilan AXIS dapat dilihat pada gambar 2 berikut ini:

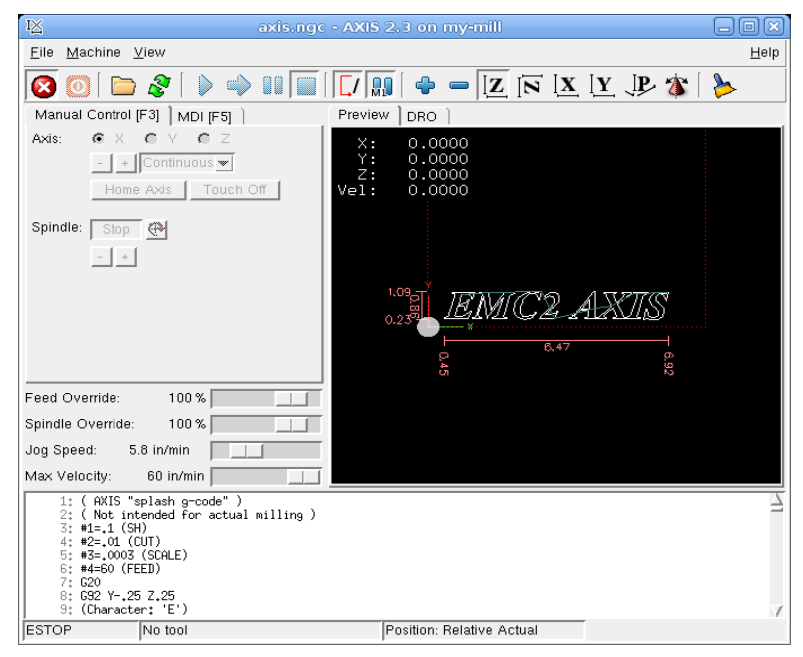

Gambar 2. AXIS Interface.

\section{Bahasa Pemrograman Python 2.6}

Program aplikasi untuk metode interpolasi Newton akan dirancang dengan menggunakan bahasa pemrograman Python 2.6 (Ascher et al., 2005). Dimana bahasa ini akan dijalankan pada perangkat lunak EMC2-AXIS yang berada di sistem operasi Linux Ubuntu. Bahasa Python adalah bahasa pemrograman dinamis yang mendukung pemrograman berorientasi objek. Di samping itu, bahasa ini mudah digunakan karena memiliki susunan tata bahasa yang jernih serta memiliki pustaka yang luas. Di samping itu bahasa Python ini dapat diintegrasikan dengan bahasa lain seperti $\mathrm{C} / \mathrm{C}++$ dan Java.

\section{G-Code}

G-Code adalah bahasa pemrograman mesin yang berkaitan erat dengan grafik dan vektor. Bahasa ini memakai komputer sebagai alat bantu penghubung antara mesin dan perangkat lunak yang 
terdapat di komputer. Mesin akan mengikuti gerak alur dari vektor yang dituliskan dalam G-Code. Bahasa pemrograman G-Code ini ditulis dalam file dengan ekstensi .ngc (Numerical G-Code). Berikut adalah beberapa contoh bahasa $G$-Code disertai dengan fungsinya masing-masing:

$\begin{array}{ll}\text { Code } & \text { Description } \\ \text { G0 } & \text { Rapid motion } \\ \text { G1 } & \text { Coordinated motion ("Straight feed") } \\ \text { G2, G3 } & \text { Coordinated helical motion ("Arc feed") } \\ \text { G4 } & \text { Dwell (no motion for P seconds) } \\ \text { G38.2..G38.5 } & \text { Straight probe } \\ \text { G80 } & \text { Cancel motion mode } \\ \text { G81, G82 } & \text { Drilling cycle without (with) dwell } \\ \text { G83, G73 } & \text { Peck and Chip-break drilling cycles } \\ \text { G85, G89 } & \text { Boring cycle without (with) dwell } \\ \text { G33 } & \text { Spindle-synchronized motion } \\ \text { G33.1 } & \text { Rigid tapping } \\ \text { G76 } & \text { Multiphase lathe threading cycle }\end{array}$

\section{Spesifikasi Mesin CNC}

Spesifikasi mesin CNC yang digunakan adalah sebagai berikut:

$\begin{array}{ll}\text { Minimum Track Width } & 0.5 \mathrm{~mm} \\ \text { Minimum Isolation Width } & 0.5 \mathrm{~mm} \\ \text { Minimum Drill Hole Diameter } & 0.6 \mathrm{~mm} \\ \text { Working Area (X/Y/Z) } & 500 \mathrm{~mm} \text { x } 400 \mathrm{~mm} \text { x } 50 \mathrm{~mm} \\ \text { Resolution } & 0.1 \mathrm{~mm} \\ \text { Travel speed (max) } & 200 \mathrm{~mm} \text { per second } \\ \text { X positioning system } & \text { dc-servo motor } \\ \text { Y/Z positioning system } & 5 \text {-phase stepper motors } \\ \text { Dimensions (W x H x D) } & 600 \mathrm{~mm} \times 500 \mathrm{~mm} \times 1500 \mathrm{~mm} \\ \text { Weight } & 300 \mathrm{~kg} \\ \text { Power supply } & 220 \mathrm{~V}, 60 \mathrm{~Hz} / 500 \mathrm{VA}\end{array}$

Mesin CNC yang digunakan dapat dilihat pada Gambar 3 berikut ini:

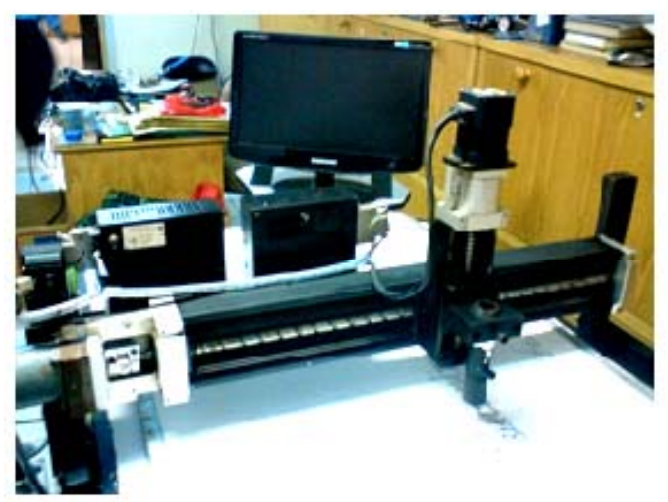

Gambar 3. Mesin CNC. 


\section{Interpolasi Newton}

Jika diberikan sekumpulan berhingga pasangan titik - titik $\left(\mathrm{x}_{1}, \mathrm{y}_{1}\right),\left(\mathrm{x}_{2}, \mathrm{y}_{2}\right), \ldots,\left(\mathrm{x}_{\mathrm{n}}, \mathrm{y}_{\mathrm{n}}\right)$ tanpa diketahui bentuk aturan fungsinya, interpolasi polinom adalah jawaban untuk membentuk kurva yang melewati pasangan titik - titik tersebut. Salah satu interpolasi polinom yang sering digunakan dalam aplikasi adalah interpolasi Newton (Kiusalaas,J, 2010)

Interpolasi Newton menggunakan pendekatan fungsi polinomial yang disusun dalam deret kombinasi $\left(\mathrm{x}-\mathrm{x}_{\mathrm{i}}\right)$ dan didefinisikan dengan:

$$
\begin{aligned}
P_{n}(x)= & a_{0}+\left(x-x_{1}\right) a_{1}+\left(x-x_{1}\right)\left(x-x_{2}\right) a_{2} \\
& \ldots+\left(x-x_{1}\right) \ldots\left(x-x_{n}\right) a_{n}
\end{aligned}
$$

Di mana koefisien $\mathrm{a}_{0}, \mathrm{a}_{1}, \ldots, \mathrm{a}_{\mathrm{n}}$ dapat dihitung dengan beda terbagi (divided differences) berikut ini:

$$
\begin{aligned}
& \nabla y_{i}=\frac{y_{i}-y_{i-1}}{x_{i}-x_{i-1}} \quad i=1,2, \ldots, n \\
& \nabla^{2} y_{i}=\frac{\nabla y_{i}-\nabla y_{i-1}}{x_{i}-x_{i-1}} \quad i=2, \ldots, n \\
& \vdots \\
& \nabla^{n} y_{n}=\frac{\nabla^{n-1} y_{n}-\nabla^{n-1} y_{n-1}}{x_{n}-x_{n-1}}
\end{aligned}
$$

Dengan beda terbagi ini, koefisien polinom dalam interpolasi Newton adalah:

$$
a_{0}=y_{0} \quad a_{1}=\nabla y_{1} \quad \ldots \quad a_{n}=\nabla^{n} y_{n}
$$

Untuk mempermudah perhitungan, biasanya akan dibuat perhitungan berikut ini (Tabel 1).

Tabel 1

Beda Terbagi

\begin{tabular}{|l||l|l|l|l|l|}
\hline$x_{0}$ & $y_{0}$ & & & & \\
\hline$x_{1}$ & $y_{1}$ & $\nabla y_{1}$ & & & \\
\hline$x_{2}$ & $y_{2}$ & $\nabla y_{2}$ & $\nabla^{2} y_{2}$ & & \\
\hline$x_{3}$ & $y_{3}$ & $\nabla y_{3}$ & $\nabla^{2} y_{3}$ & $\nabla^{3} y_{3}$ & \\
\hline$x_{4}$ & $y_{4}$ & $\nabla y_{4}$ & $\nabla^{2} y_{4}$ & $\nabla^{3} y_{4}$ & $\nabla^{4} y_{4}$ \\
\hline
\end{tabular}

Di mana koefisien polinom dalam interpolasi Newton adalah nilai pada diagonal dalam Tabel $1 \mathrm{di}$ atas.

\section{Implementasi Program}

Untuk implementasi program aplikasi ini memerlukan beberapa tahapan berikut: (1) pembuatan Virtual Control Panel yang terintegrasi dengan AXIS melalui PyVCP. Langkah ini akan menghasilkan file .xml; (2) mengkoneksikan PyVCP dengan EMC2 melalui fasilitas HAL (Hardware Abstraction Layer). Langkah ini akan menghasilkan file .hal; (3) mengatur ulang konfigurasi mesin CNC di dalam file axis_mm.ini agar membaca file .xml dan file .hal yang telah dibuat yaitu pada 
bagian PYVCP dan POSTGUI_HALFILE; (4) membuat program utama dalam bahasa Python, yang akan menghasilkan G-Code dalam file .ngc; (5) mengeksekusi file .ngc dari AXIS Interface.

\section{HASIL DAN PEMBAHASAN}

\section{Pembuatan Virtual Control Panel}

Untuk membuat GUI Interpolasi Newton seperti pada Gambar 4 di bawah ini diperlukan pembuatan file .xml untuk mengatur tampilan tersebut. Dalam implementasi, file ini dinamai interpolasi.xml yang isinya dapat dilihat sebagai berikut:

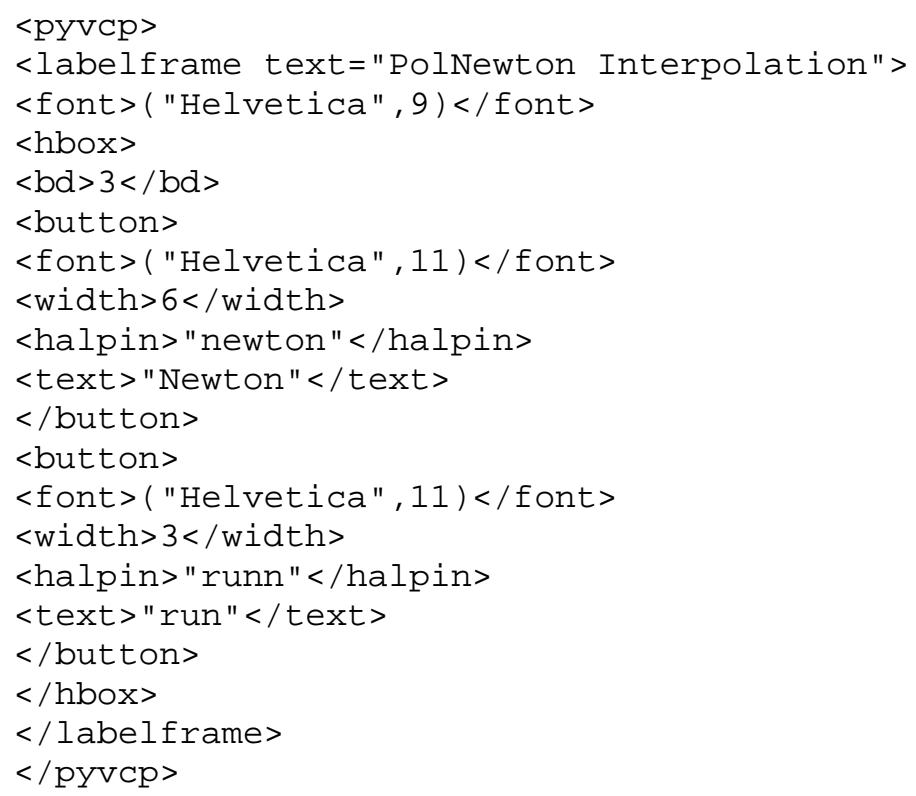

Dalam file interpolasi.xml yang pertama kali membuat tag <pyvcp>. PyVCP (Python Virtual Control Panel) dibutuhkan untuk melakukan suatu virtualisasi panel di perangkat lunak EMC2. Bentuk virtualisasi panel ini dibutuhkan karena perangkat lunak EMC2 mengenal panel sebagai suatu objek yang telah dibuat pada perangkat lunak tersebut. Dalam implementasi ini, virtualisasi panel dengan PyVCP dipakai sebagai penghubung (connector) antara perangkat lunak EMC2 dengan program interpolasi yang telah dibuat.

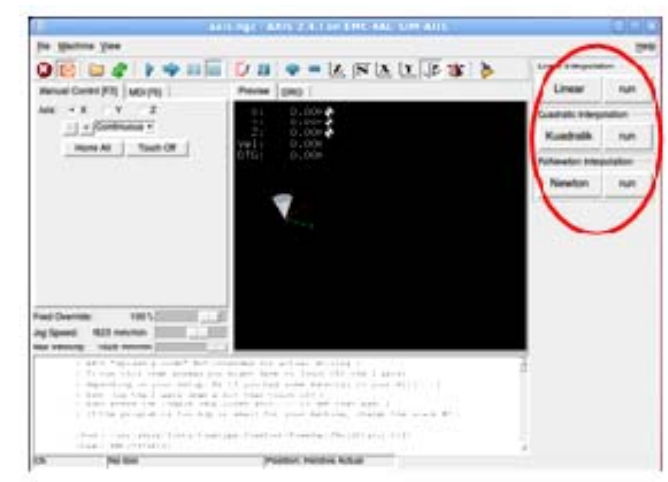

Gambar 4. GUI interpolasi Newton. 


\section{Mengkoneksikan PyVCP dengan HAL (Hardware Abstraction Layer)}

HALUI (Hardware Abstraction Layer User Interface) adalah salah satu fungsi dalam perangkat lunak EMC2 yang digunakan untuk membuat suatu sinyal dan port sehingga GUI yang dibuat dengan PyVCP dapat terkoneksi dengan mesin CNC nya (HAL Manual, 2011). Untuk itu dibuat file hal untuk membuat koneksi sinyal melalui port tertentu pada perangkat lunak EMC2 ke mesin $\mathrm{CNC}$ dan dalam implementasi file ini dinamai interpolasipostgui.hal yang isinya dapat dilihat sebagai berikut:

net btn5 halui.mdi-command- $\odot 4<=$ pyvcp. newton

net btn6 halui.mdi-command-05<= pyvcp.runn

\section{Mengatur Ulang Konfigurasi Mesin CNC}

Dalam perangkat lunak EMC2-Axis ini, terdapat file .ini (initial) dimana file tersebut akan menyimpan dan memanggil semua pengaturan yang ada untuk ditampilkan ketika perangkat lunak EMC2 dipanggil. File ini dapat diakses oleh pengguna dan dapat dimodifikasi sesuai dengan kebutuhan. Untuk implementasi interpolasi Newon, digunakan file axis_mm.ini dan dilakukan beberapa pengaturan pada file tersebut. Modifikasi file .ini terutama agar perangkat lunak EMC2 dapat membaca file .xml dan file .hal yang telah dibuat yaitu pada bagian PYVCP dan POSTGUI HALFILE.

\section{Membuat Interpolasi Newton dengan Python}

Metode interpolasi Newton diimplementasikan melalui program Python 2.6 dalam sistem operasi Linux Ubuntu, Perangkat lunak EMC2-Axis tersebut memanggil program Python dalam pengoperasiannya melalui fasilitas MDI commands pada HALUI (Hardware Abstraction Layer) dan mengeksekusi perintah G-Code M101...M199 (User-defined M-codes). Selain itu untuk membuat GUI pada Python untuk menginput data interpolasi digunakan Tkinter (Swipman,et al, 2010). Program interpolasi Newton yang dibuat dengan bahasa pemrograman Python akan menghasilkan file yang berupa G-Code (file .ngc). Dalam implementasi, file Python dinamai M101 dan hasilnya berupa file 101.ngc yang isinya dapat dilihat sebagai berikut:

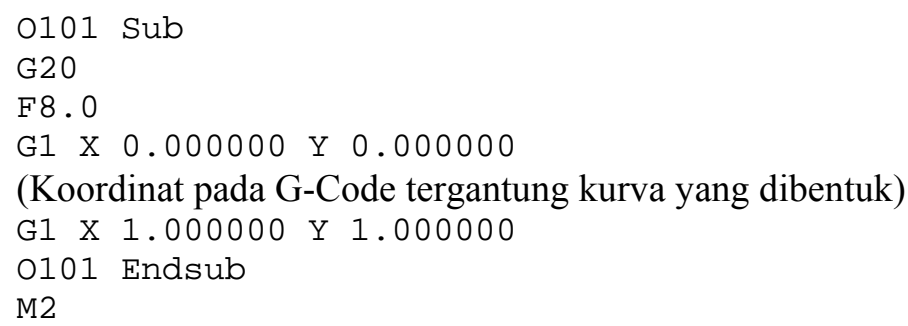

\section{Mengeksekusi File .ngc dari AXIS}

Setelah file .ngc terbentuk maka file tersebut dapat dipanggil melalui fasilitas MDI commands pada HALUI (Hardware Abstraction Layer) dan mengeksekusi perintah G-Code O101...O199 (Call Subroutines). Untuk melakukan ini, pengguna cukup mengklik tombol Run yang sudah dibuat dengan PyVCP. 


\section{PENUTUP}

Untuk mempercepat proses kinerja dalam suatu industri yang memakai mesin CNC, seringkali dibutuhkan customization atau pengubahsesuaian mesin misalnya untuk membuat kurva berdasarkan beberapa data tertentu dan metode interpolasi Newton dapat memenuhi kebutuhan untuk membuat kurva ini. Dengan menggunakan perangkat lunak EMC2 yang bersifat terbuka sehingga dapat dimodifikasi dengan relatif mudah, dapat diimplementasi metode interpolasi Newton dengan bahasa pemrograman Python pada mesin CNC yang digunakan. Hasil pengujian interpolasi Newton pada mesin $\mathrm{CNC}$ telah dapat berjalan dengan baik sampai dengan 4 pasang data masukan dan untuk masukan yang lebih banyak akan menimbulkan osilasi pada kurva hasil interpolasi. Penelitian ini merupakan contoh bagaimana mesin $\mathrm{CNC}$ dapat dikustomisasi sehingga dapat memenuhi kebutuhan yang spesifik.

\section{DAFTAR PUSTAKA}

Ascher, D., Martelli, A., Ravenscroft, A. (2005). Python Cookbook. California: O’Reilly.

Kiusalaas, Jaan. (2010). Numerical Methods in Engineering with Python. Pennsylvania: Pennsylvania State University.

Smid, P. (2003). CNC Programming Handbook, (2nd edition). New York: Industrial Press.

Starovešk, T., Brezak, D., Udiljak, T., \& Majetić, D. (2009). Implementation of a Linux-based CNC open control system. 12th International Scientific Conference on Production Engineering CIM.

Swipman, John W. (2010). Tkinter 8.4 Reference: a GUI for Python. Mexico: New Mexico Tech. 